\title{
ADVERTISING ON CITY BUSES
}

\author{
Ana Dujmović, Nace Pušnik \\ University of Ljubljana, Faculty of Natural Sciences and Engineering, \\ Department of Textiles, Graphic Arts and Design, Ljubljana, Slovenia
}

\begin{abstract}
Public transportation became a prime carrier of "moving images" in many consumer cultures. The main interest was to investigate how many advertisements participants can retrieve from memory and what was their general opinion on outdoor advertising. A field and online survey (both in form of questionnaire) were carried out in a group of 1200 participants. They were divided in six groups and analyzed according to their age, gender and frequency of using the public transportation. The results indicate that memory of outdoor advertising decreases with age. The participants most frequently agreed with the assertion/claim that outdoor advertisement on city buses of Ljubljana impedes the outside view through the window of the bus making it difficult to orient themselves according to surrounding. Advertisers could take this into account and avoid posting ads on the bus windows, or limit this to the parts where ads are least distracting the users.
\end{abstract}

Key words: cityscape, city bus transport, memory, outdoor advertising, user experience

\section{INTRODUCTION}

Advertising is a part of our lives and we find it hard to avoid it. Advertisements (in further text ad-singular and ads-plural) are thus present almost everywhere; in various media, such as radio, television, newspapers and magazines, on the internet. They also appear in public places. Posters of different sizes are placed in a variety of places, e.g. along roads, bus stops, in bars and on vehicles. In Ljubljana, outdoor ads that can also cover glass surface were placed on city buses in 2009 (before that, just non-glass parts could be covered). Advertising is a broad concept, often associated with ads and businesses. Businesses often advertise themselves and their brands, but the concept of advertising is not just tied to them (Ackley and Hackley, 2015; Bernays, 2005). Politicians, political parties and non-governmental organizations are also advertised. Advertising is a paid, impersonal form of communication with which we want to encourage the process of exchanging products, services or ideas (Ackley and Hackley, 2015; Bernays, 2005). When we talk about advertising political campaigns and politics, we often use the word propaganda, which means spreading beliefs in our favour (De Pelsmacker et al, 2008). The difference between propaganda and advertising is in the establishment of a communication relationship between the sender and the recipient. Advertising and other forms of marketing communication must fulfill the promises made, as they may otherwise be subject to legal or market sanctions. Propaganda are often vague promises that are supposed to happen in a long and indefinite period of time and are not subject to criminal sanctions if they are not fulfilled or are false (De Pelsmacker et al, 2008).

With advertising we want to achieve pre-set goals, e.g. increase or maintain sales, and it is difficult to measure the actual effectiveness and performance of a campaign. The reach of a set of published messages or the reach of an entire campaign is often measured. Companies are interested in the effect of their advertising, as they can devote a large part of their resources to this. The affinity index is often used, which is calculated as the ratio between the reach of the media carrier in the target audience and the reach of the carrier in the entire population (Allaby, 2020; Loken, 2006).

In evaluation, two concepts emerge that are often equated, although there is a difference between them. The concept of performance is related to achieving the goals we have set, or changes caused by the ad in the recipient's response. Efficiency is related to the profitability of advertising with optimal use of resources. The results of sales before and after the advertising campaign are often compared; we can also focus on other parameters, e.g. brand recognition. It has been proven that efficiency increases the most when the target group are users who are not yet familiar with the brand (De Pelsmacker et al, 2008). 
When measuring efficiency and effectiveness, we distinguish several types of goals:

- $\quad$ sales targets relating to increasing or maintaining sales or market share;

- media goals that show the target group's exposure to the campaign message;

- communication goals, which are measured by various techniques, e.g. call up the ad (De Pelsmacker et al, 2008; Loken, 2006)

Professors Jennifer Gregan-Paxton and Barbara Loken (Gregan-Paxton and Loken, 1996) researched how people store information. They found that elapsed time and saturation of the space with information affect the effectiveness of advertising. The longer it takes from the moment a person is exposed to an ad, the less likely they are to retrieve information. Even if a person sees the same ad more than once, she/he will probably not remember it.

It has been investigated that emotions play an important role in consumer decision making. For effective advertising, only superficial automatic detection is enough, as the evaluation of messages is largely subconscious. Ads should also contain an emotional component, because this is what allows the ad to leave traces in the long-term memory (Gregan-Paxton and Loken, 1996; Kovačić, 2011).

Advertising messages can be measured before or after the campaign. The effects of the campaign are measured; whether we have achieved the set goals or not. We know quite a few methods of measuring ads, which are mostly used before the start of advertising, e.g. concept testing, preliminary testing, diagnostics, key concept, readability assessment, psychological test, recall test, direct opinion on the ad, indirect opinion on the ad (Ackley and Hackley, 2015; De Pelsmacker et al, 2008).

Outdoor advertising is a sub-meaning of out of home advertising, which is divided into ambient or indoor and outdoor advertising or outdoor advertising (Ackley and Hackley, 2015; Tsuji, n.d.). Internal media can be billboards in waiting rooms, cinemas, shops, shopping centers, etc. Outdoor media include ads that can be placed along roads, on the street, at bus, train stations and in a variety of places, including benches, trash cans and means of transport. These are large posters, smaller poster areas of various dimensions, ads in light showcases. They are made to distract human attention, so they often contain a simple message and a screaming visual image.

Vehicle advertising is one of the options for outdoor advertising. The ad can be placed on the outside of any vehicle, usually special foils are used, which are glued over the vehicle frame. Outdoor advertising is used on buses, trucks, trains, cars, motorcycles, bicycles... This type of advertising achieves high exposure. According to the Target Group Index, 29 million people in the UK are exposed to outdoor ads on buses every week (Tsuji, n.d.; Mrgole, 2017).

Bus advertising is part of vehicle advertising. The bus usually changes its daily lines, so in a few days the same ad can appear in different parts of the city. The large area of the bus allows various forms of ads that attract attention. Increasingly, entire buses are covered except for windows next to the driver. It can be advertised inside the bus or on the outside. Businesses prefer to advertise on the exterior surfaces of city buses rather than intercity buses. Intercity buses travel more kilometers than city buses, but are less exposed to people. There is a higher frequency of people in cities compared to driving on local roads.

A different percentage of the bus's exterior can be covered (Figure 1), and the ads can also cover the glass surfaces, the back or only certain parts. The left side and rear side are more visible to drivers of other vehicles and pedestrians, so in principle it is designed slightly differently than the right side, which is intended for those waiting at the bus station (Mrgole, 2017; Phillips and Stanton, 2004).
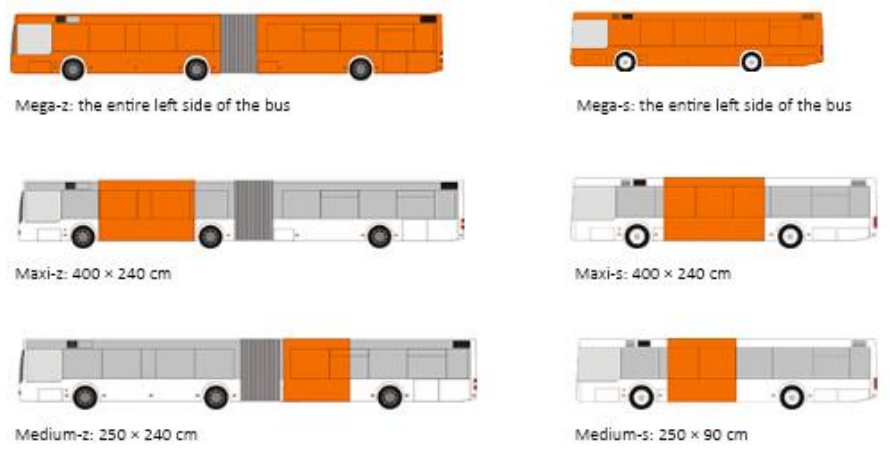

Figure 1: Advertising options on the left side of the bus (Media Bus, n.d.) 


\section{METHODS}

We conducted two surveys - field and online. The main topics of the surveys were the use of the city bus in Ljubljana and the opinion on outdoor ads on buses in Ljubljana. We included 1200 people; 600 were obtained through a field survey and 600 through an online survey. Respondents were divided into six age groups. Each age group consisted of 200 respondents of which exactly 100 were female and 100 were male. In the whole survey this represents 600 women and 600 men evenly distributed by age groups. The surveys covered the same questions, but in a different sequence. The six age groups of both surveys were: up to 24 years old; from 25 to 34 years old; from 35 to 44 years old; from 45 to 54 years old; from 55 to 64 years old; over 65 years old.

The surveys consisted of seven questions. All questions allowed the choice of only one answer. The first question referred to the frequency of use of the city bus in Ljubljana, the respondents chose between six options. The second question was used to determine whether people had noticed at least one outdoor ad on a city bus in Ljubljana in the last week, and the third question allowed people to write the answer themselves. We were interested in whether people could mention at least one ad that was on the outside of the city bus in Ljubljana in the last week. The fourth question consisted of eight statements referring to outdoor ads on city buses in Ljubljana; the respondents decided on a five-point scale (from strongly disagree to completely agree) how much they agree with the statements. The fifth question asked about gender (male or female), the sixth question ranked respondents into the above age groups. The seventh question referred to employment status.

We set up five hypotheses.

- Hypothesis 1: 70\% or more of the respondents noticed at least one outdoor ad on a city buses in Ljubljana in the last week.

- Hypothesis 2: 50\% or more of the respondents can state at least one advertising message that was on the outer part of the city buses in Ljubljana in the last week.

- Hypothesis 3: 60\% or more of the respondents think that outdoor ads on city buses in Ljubljana are interesting.

- Hypothesis 4: 50\% or more of the respondents believe that outdoor ads on city buses in Ljubljana are an unobtrusive way of advertising.

- Hypothesis 5: 75\% or more of the respondents believe that outdoor ads on city buses in Ljubljana obstruct the view through the bus window.

\section{RESULTS}

\subsection{Combined Results of Field and Online Survey}

We first analyzed the demographic data of the respondents, such as employment status. Figure 2 shows the employment status of the respondents; the answers are sorted by age groups. Most, 663 (55.3\%) of all participants are employed. Among those under the age of 24, the largest is number of students (174, 87.0\%), 14 (7.0\%) high school students and 12 (6.0\%) employees. There were 106 (53.0\%) employees, 86 (43.0\%) students and 8 (4.0\%) unemployed in the age group of 25 to 34 years. The groups aged 35 to 44 $(183,91.5 \%), 45$ to $54(183,91.5 \%)$ and 55 to $64(171,85.5 \%)$ had the largest share of employees. In the age group over 65 , most retirees $(192,96.0 \%)$ were expected.

Most respondents answered from time to time the question "How often do you use the city bus in Ljubljana?". There were 474 (39.5\%) of them. The analysis by age groups among the respondents shows that people under 24 most often use the city bus four to six times a week, 66 (33.0\%) of them in their age group, slightly less, 52 (26.0\%) chose to use the city bus every day (Figure 3 ). In the remaining age groups respondents most often use the city bus in Ljubljana occasionally. 132 (11.0\%) of all respondents do not use the city bus in Ljubljana. According to LPP's annual report for 2017, 82.5\% used the city bus in 2018, and our analysis showed an even higher share; 1068 (89.0\%) of respondents use the bus in Ljubljana at least occasionally. 


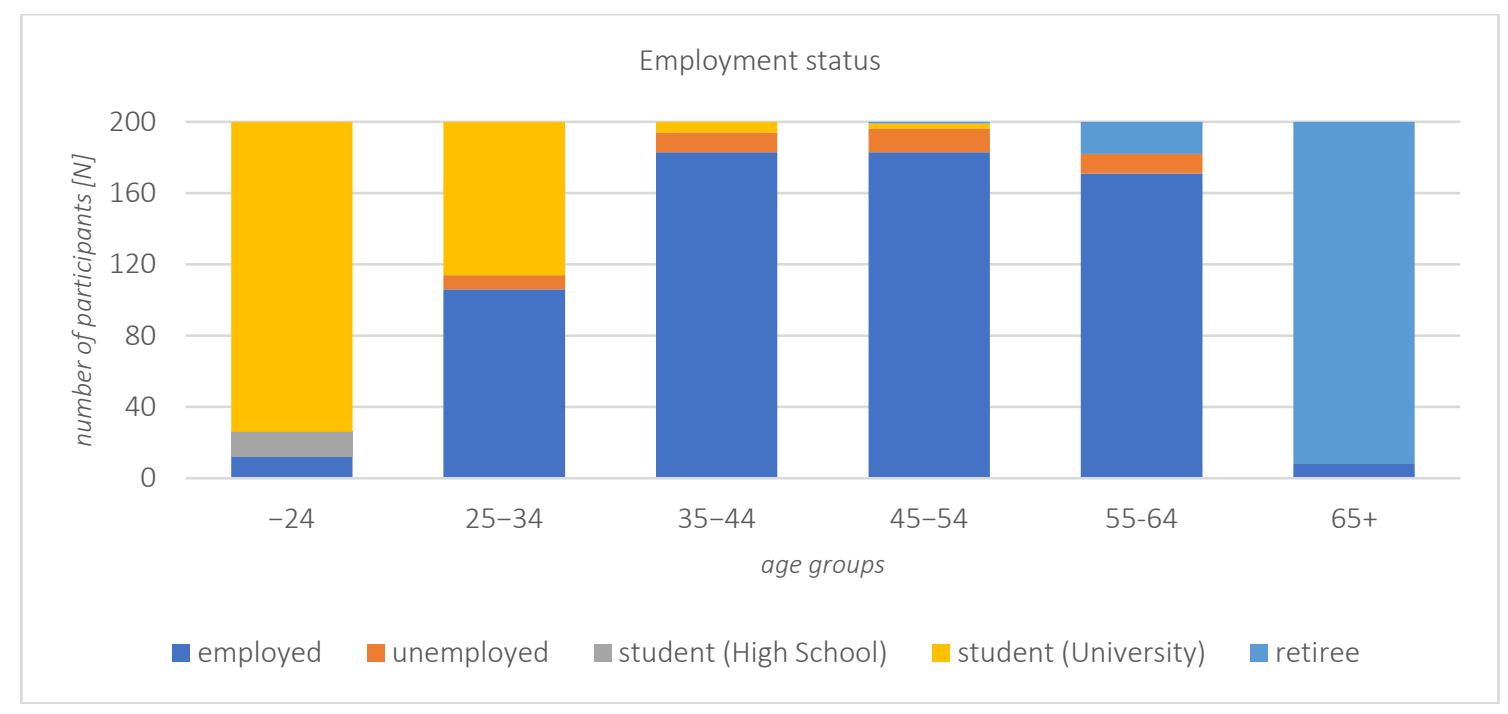

Figure 2: Display of the answer by age groups to the question "What is your employment status?"

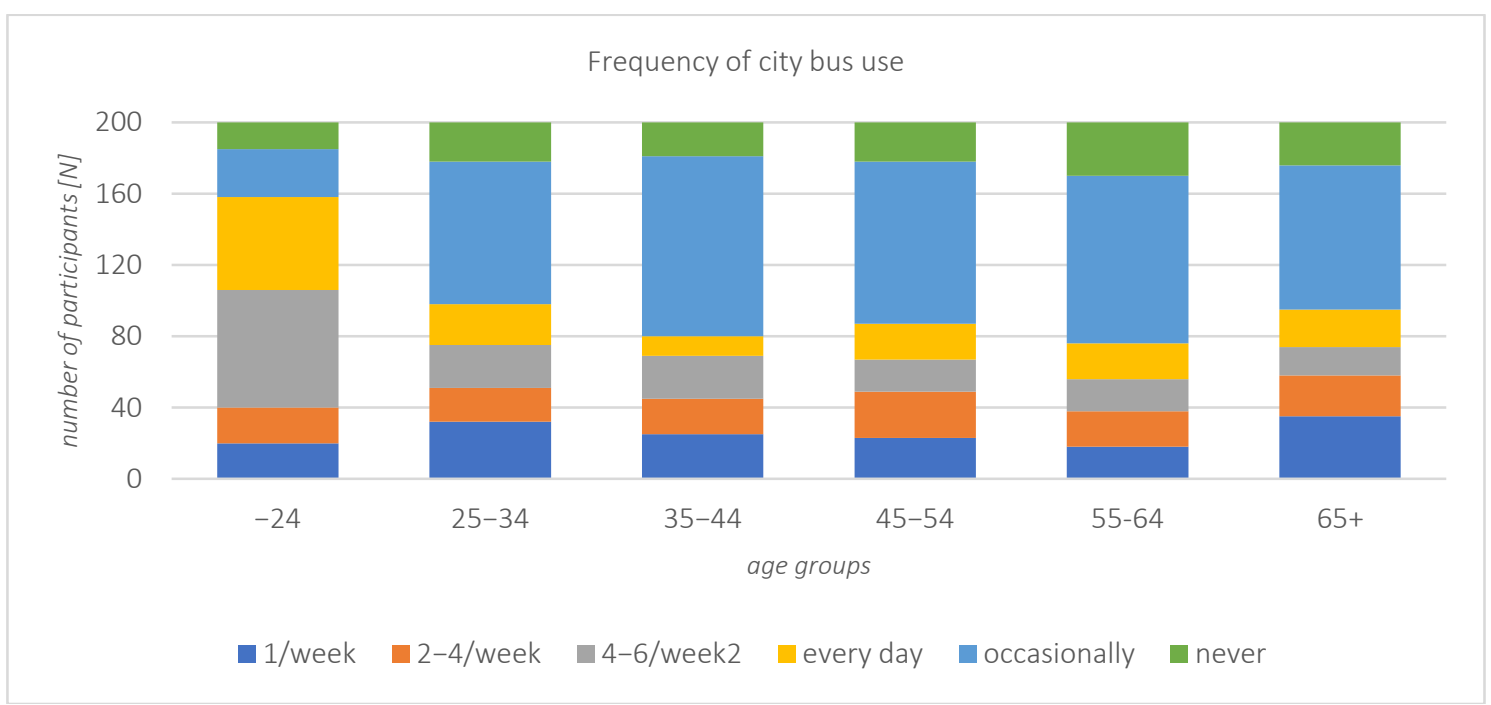

Figure 3: Display of the answer by age groups to the question "How often do you use the city bus in Ljubljana?"

The difference could be explained by the fact that young people under the age of 24 mostly do not earn enough, as most of them are not regularly employed to be able to afford a car, so they use public transport more often.

Figure 4 shows that most respondents noticed at least one outdoor ad on a city buses in Ljubljana in the last week. Most, 176 (88.0\%) were in the first age group, up to 24 years old. The lowest number of ads was noticed by people over 65 (152, 76.0\%). 218 (18.2\%) of all respondents did not notice ads on the city buses in Ljubljana in last week. 


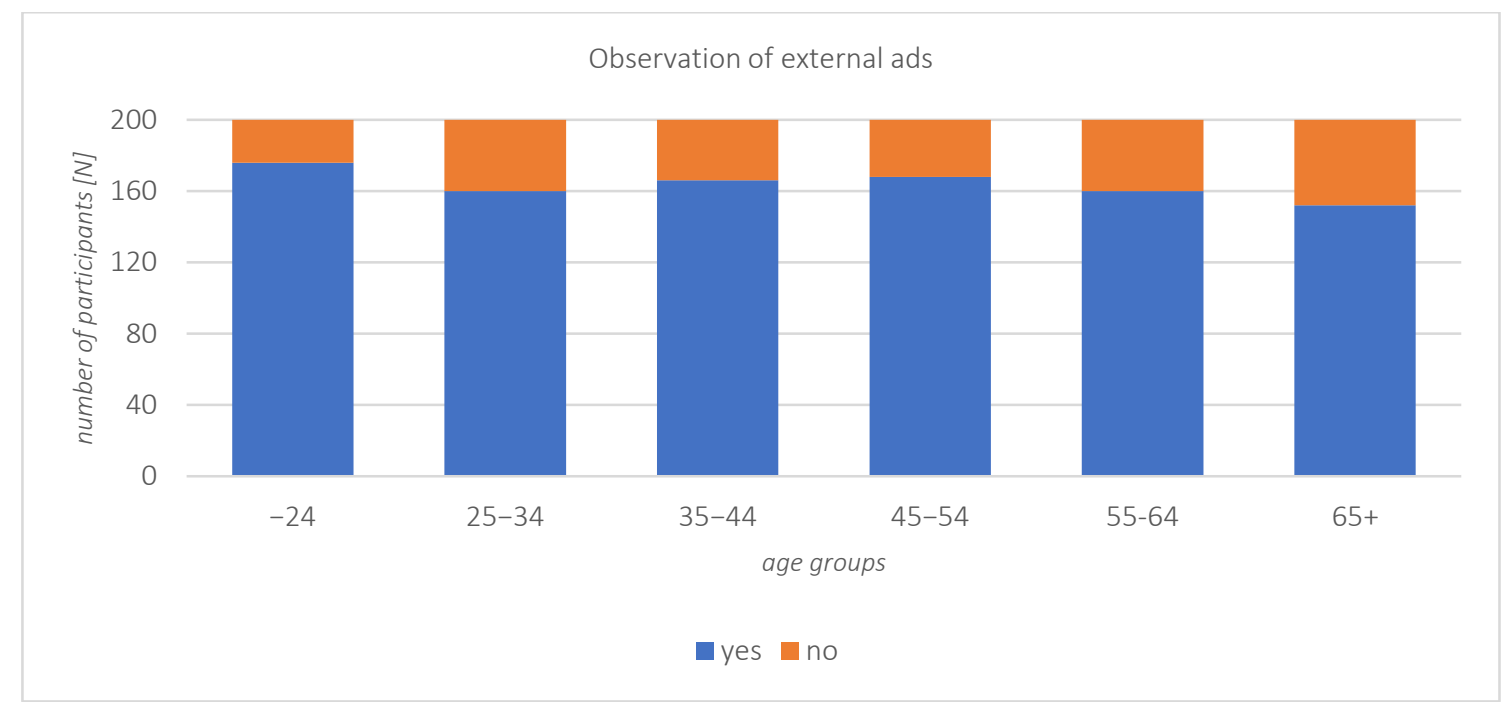

Figure 4: Display of the answer by age groups to the question

"Have you noticed at least one outdoor ad on the city bus in Ljubljana in the last week?"

$225(18.8 \%)$ respondents mentioned at least one ad that was on the outside of the city buses in Ljubljana. People under the age of 24 most often mentioned an ad, 69 (34.5\%). The least frequently reported ads were in the age groups 55-64 (176, 88.0\%) and over 65 (176, 88.0\%) (Figure 5). The indication of ads with higher age group is declining.

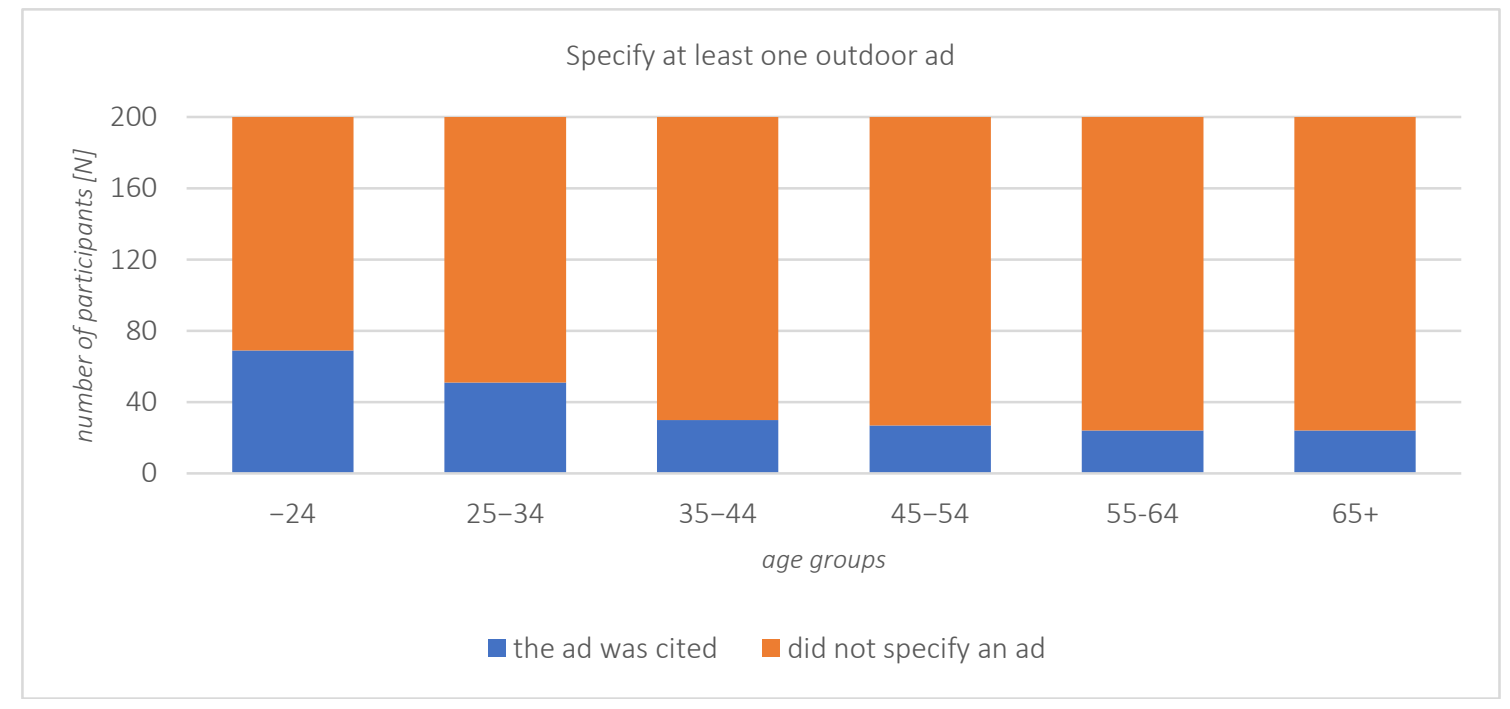

Figure 5: Display of the answer by age groups to the question

"Can you list at least one ad that was on the outside of the city bus in Ljubljana in the last week?"

People between the ages of 18 and 35 are more likely to remember information from ads, but it is harder to persuade them to make a purchase compared to a group that is older than 35 . Older people are less likely to remember information, but tend to make a purchase quicker. On the other hand, it has been shown that if the ads contain words or phrases such as new, new product, improved performance, this convinces the group of 18 to 35 old years more; people over the age of 35 are less susceptible to such messages. (Phillips and Stanton, 2004)

Those who use the bus once a week $(153,12.8 \%)$, four to six times a week $(166,13.8 \%)$ and every day $(147,12.3 \%)$ cited an ad as shown by the values in parentheses. People, who use buses two to three times a week cited an ad in $128(10.7 \%)$ cases. 474 occasional users (39.5\%) have listed the most ads. Those who never use bus $(132,11.0 \%)$ had the lowest percentage of recollecting an ad from their memory. This actually means they do not pay attention to buses even if they are just walking in city center where fluctuation of buses is the highest (Figure 6). 


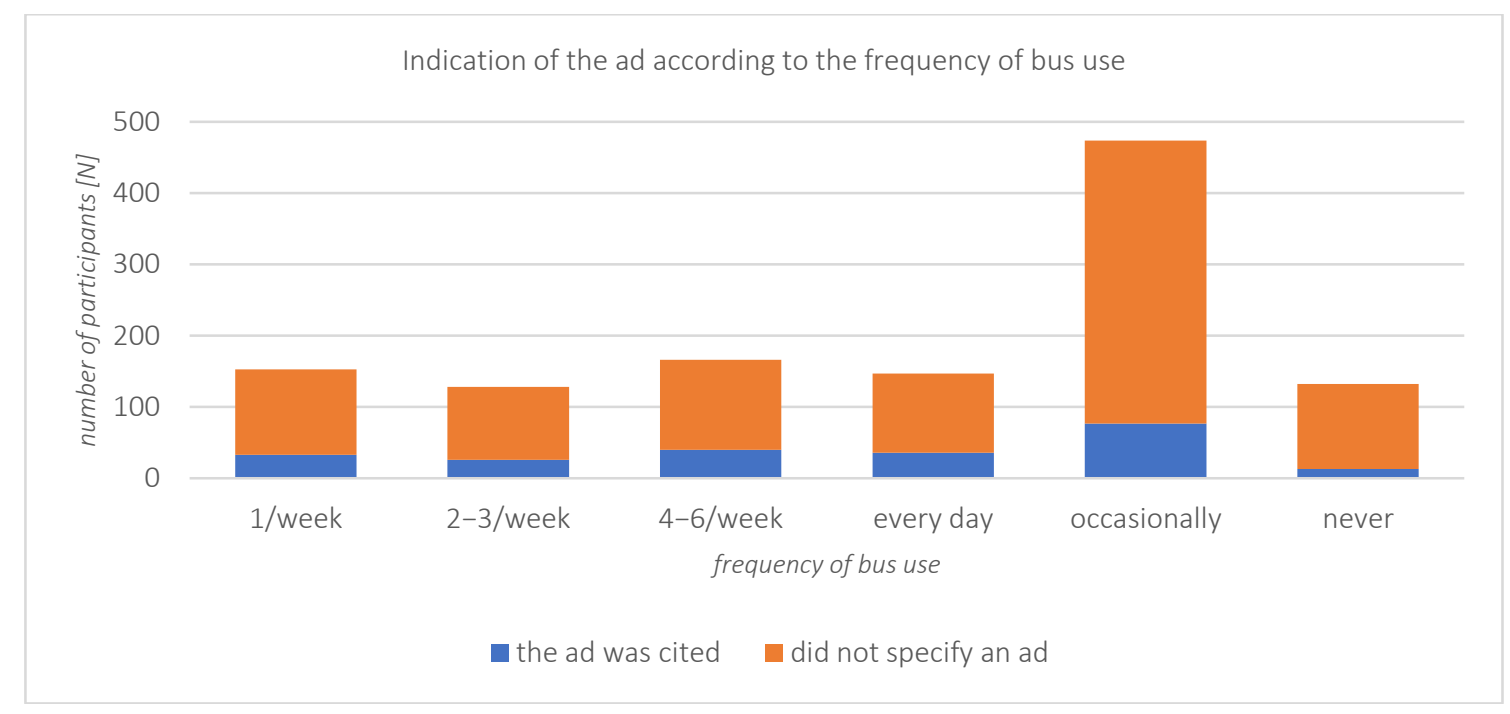

Figure 6: Display of the answer according to the frequency of bus use to the question "Can you list at least one ad that was on the outer part of the city bus in Ljubljana in the last week?"

Figure 7 shows the ads that respondents noticed on the outside of the city bus. Ads that have been listed at least three times are displayed. $18(2.0 \%)$ respondents mentioned School B2, which was also the most common answer. 93 of the 225 listed ads were different. 32 responses (some repeated) stated an ad, but it was not written which company or slogan it was. Some examples of such messages: a man, crocodile, something blue - theater, for tires, news, sausage, time ad.

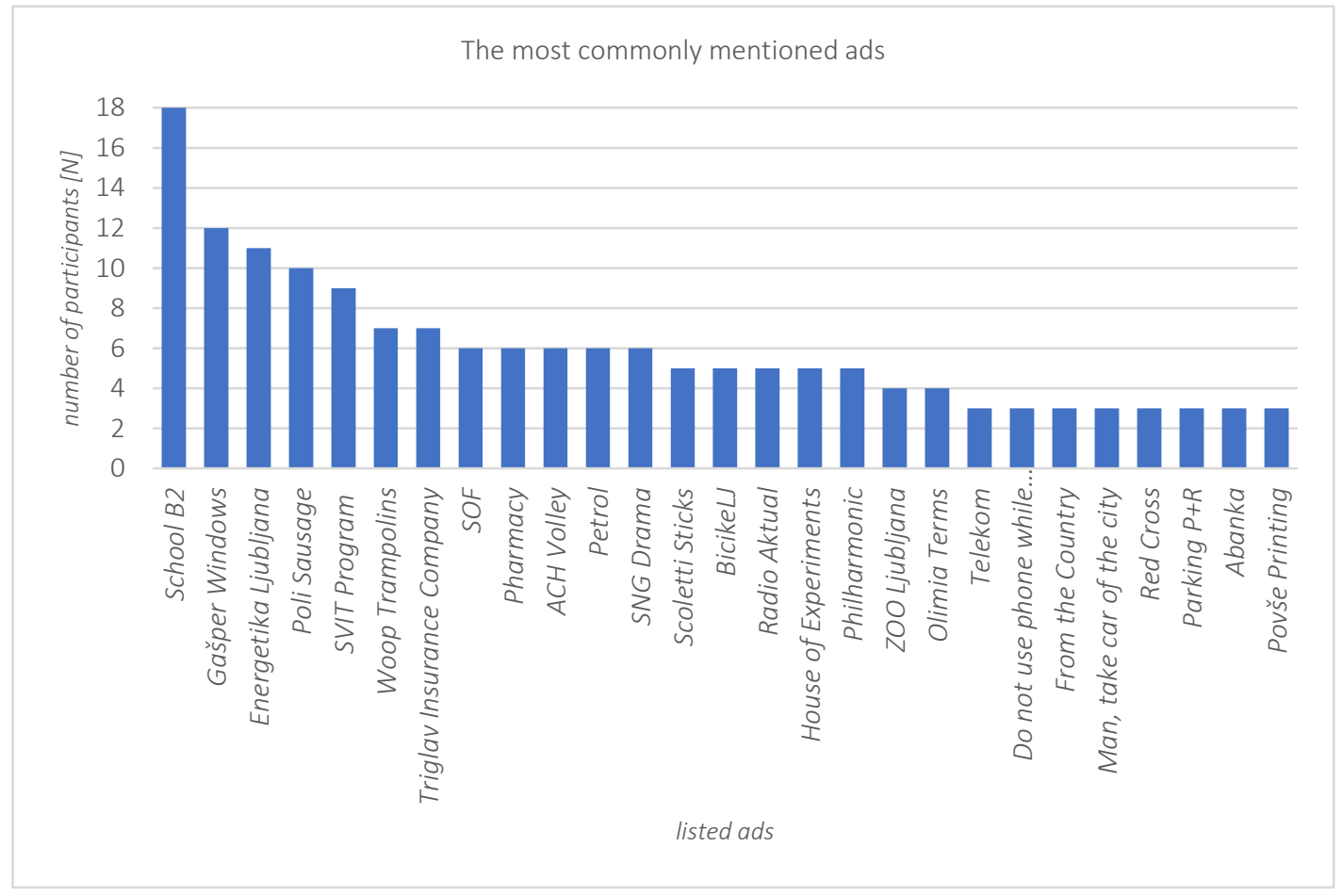

Figure 7: Display of the most frequently mentioned ads that the respondents noticed on the outer part of the city bus

Figure 8 shows the ad for School B2 that respondents most often cited. 13 (7.0\%) respondents in the age group up to 24 years old mentioned this ad; 2 (1.0\%) from the age group of 25 to 34 and 55 to 64 years and $1(0.5 \%)$ from the age group over 65 years old. The ad is bright pink with a large company logo and a photo of a smiling woman. The ad occupies the entire section below and above the windows. Part of the windows are covered with inscriptions and photography of a woman. The letters are large enough to be visible even when standing on the sidewalk or the other side of the road. 


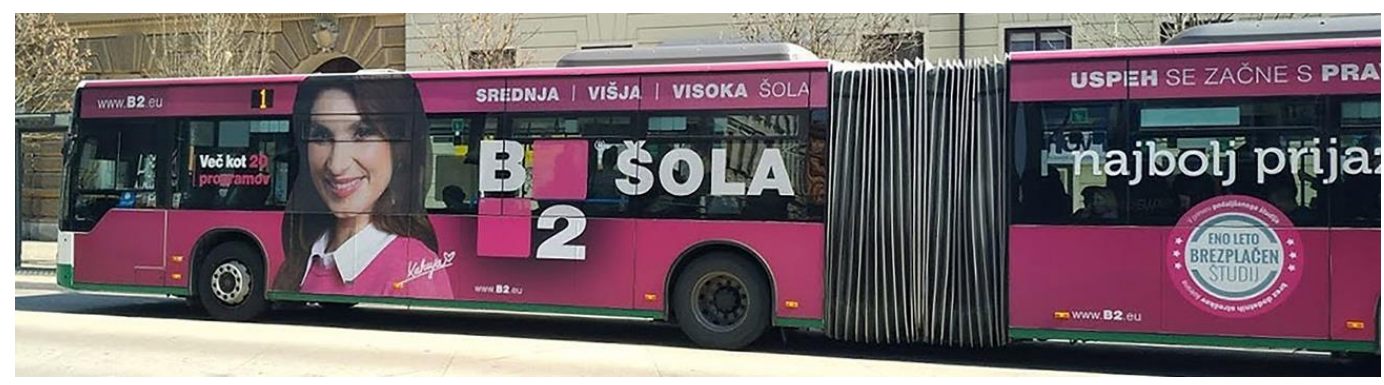

Figure 8: Ad for school B2 (Photo: A. Dujmović)

Figure 9 shows an ad for Windows and Doors Gašper. 5 (2.5\%) respondents from the age group up to 24 years wrote this answer, 2 (1.0\%) from the age groups from 25 to 35 years, from 35 to 44 years and over 65 years and $1(0.5 \%)$ respondent from the age group from 55 to 64 years. The ad on the right side of the bus, as seen in the photo (Figure 9) covers the entire right area with the exception of the door and the first window. All exit doors also have the company logo. The logo has been used at least nine times in one side of the bus. Shades of green and brown predominate. In addition to green, various wood textures and a photography of a worker holding a window frame, a company phone number, a website and some other text are used.

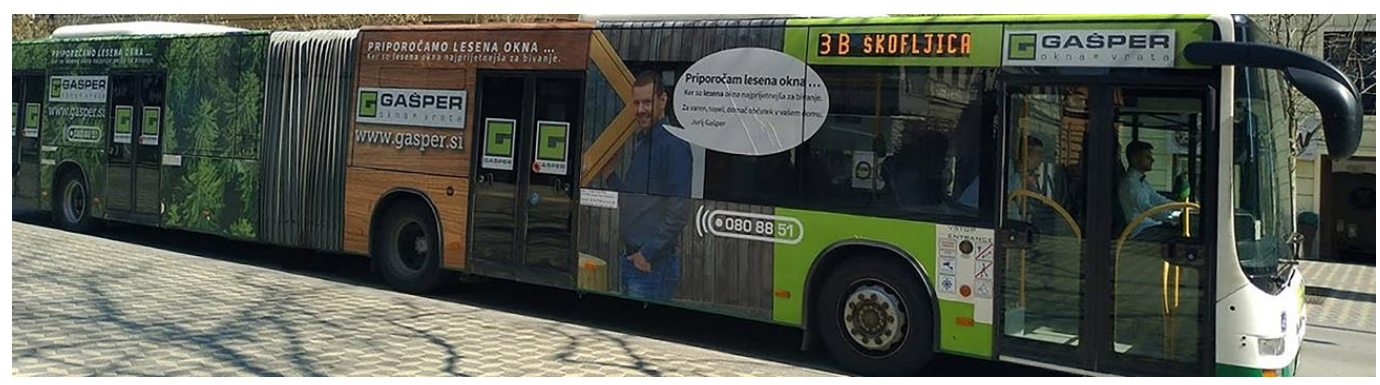

Figure 9: Ad for Windows and doors Gašper (Photo: A. Dujmović)

The ad for Energetika Ljubljana was mentioned by 3 (1.5\%) respondents in group 35 to 44 years old; 2 (1.0\%) from the age groups up to 24 , from 55 to 64 , over 65 and $1(0.5 \%)$ respondent from the age groups 25 to 34 and 45 to 54 years old. Figure 10 shows a smaller city bus that has no creases. The ad covers part of the bus under and above the windows, smaller red stickers are on all windows of the right side of bus, and the exit doors are covered with inscriptions and small illustrations.

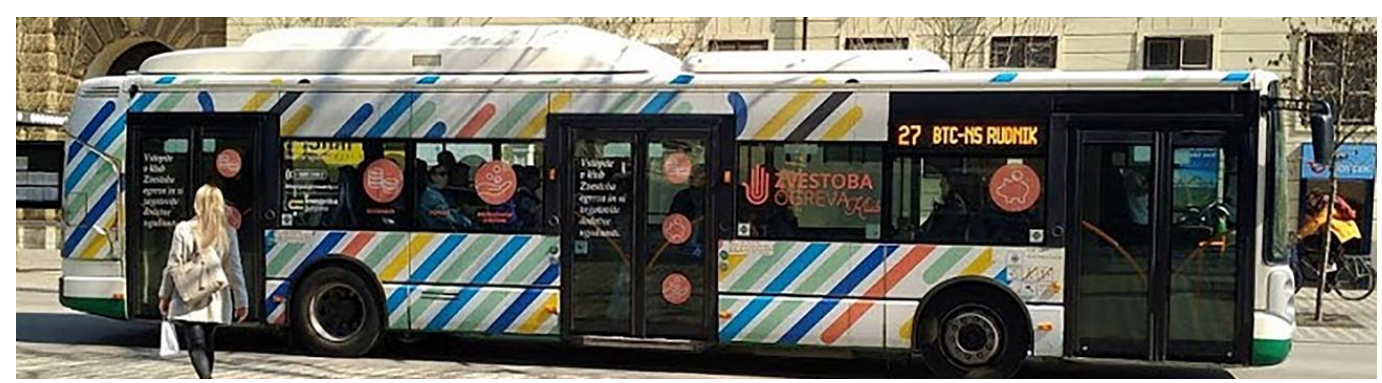

Figure 10: Ad for Energetika Ljubljana (Photo: A. Dujmović)

The ad for the SVIT Program was remembered by 4 (2.0\%) respondents from the age group 25 to $34 ; 2$ (1.0\%) from each of the groups 35 to 44 and over 65 , and 1 (0.5\%) respondent from group up to 24 years old. The SVIT program is intended for women and men between the ages of 50 and 74, but the ad is mostly remembered by young people. Only 9 respondents mentioned this ad so we cannot assess whether it reaches the desired target audience on the basis of this data; we assume they are women and men between the ages of 50 and 74 . The ad covers the entire section below and above the windows. It is mostly orange with the exception of an illustration of a roll of white paper on which the slogan is written (Figure 11). 


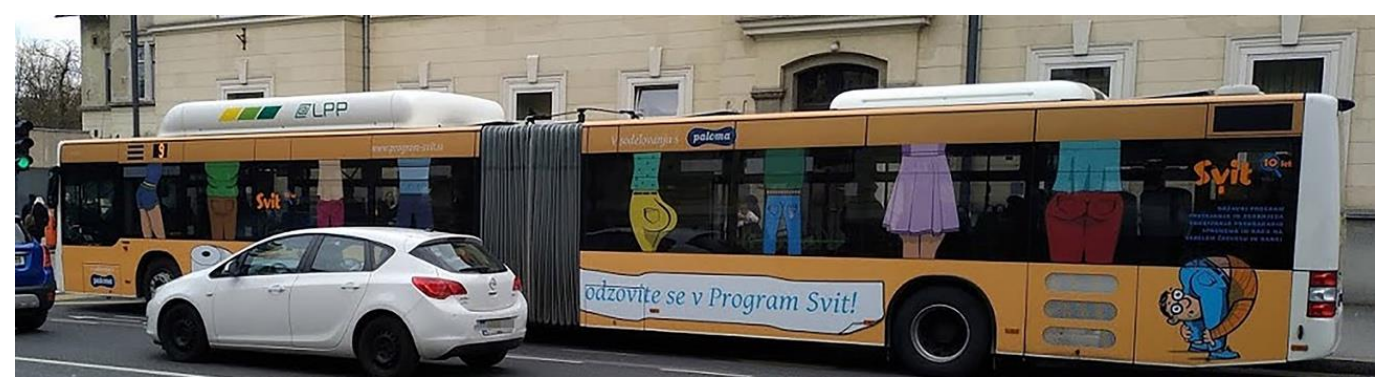

Figure 11: Ad for SVIT Program (Photo: A. Dujmović)

$5(2.5 \%)$ respondents under the age of 24 and $2(1.0 \%)$ respondents between the ages of 25 and 34 cited an ad for Woop! This ad covers the entire area under the bus windows and above them; the exit doors are covered throughout. With the exception of the first door and window, areas are mostly covered (Figure 12). The ad follows the corporate visual identity of the company being advertised; the background of the ad is dark, and the remaining elements are pink, blue, yellow and white. For reasons stated, ad is well visible from a distance. There are almost no inscriptions on the ad, in addition to the graphic elements, there is the company logo, the logo of the acrobatic group Dunking Devils and a key.

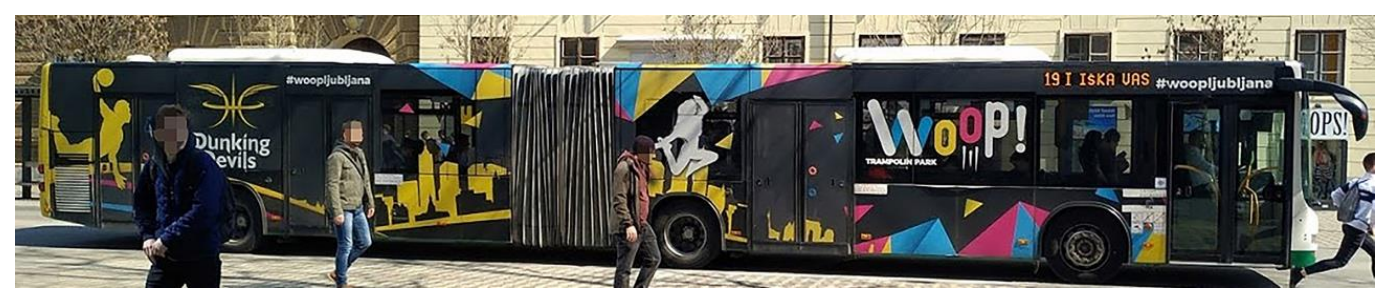

Figure 12: Trampoline ad Woop! (Photo: A. Dujmović)

Figure 13 shows an ad cited by 3 (1.5\%) respondents. It is one of the few smaller ads mentioned in the survey. The ad is in the shape of a pastel green circle between the wheels of the bus, which is used for the background; the letter $P$ is well visible, partly also $R$, but the contrast between the background and the letters is poor. From a distance you can also see what is written under the letters; the larger inscription (park and transfer) below can be noticed with some effort while the smallest text is poorly visible, almost unreadable, and the contrast between gray and pastel green is poor.

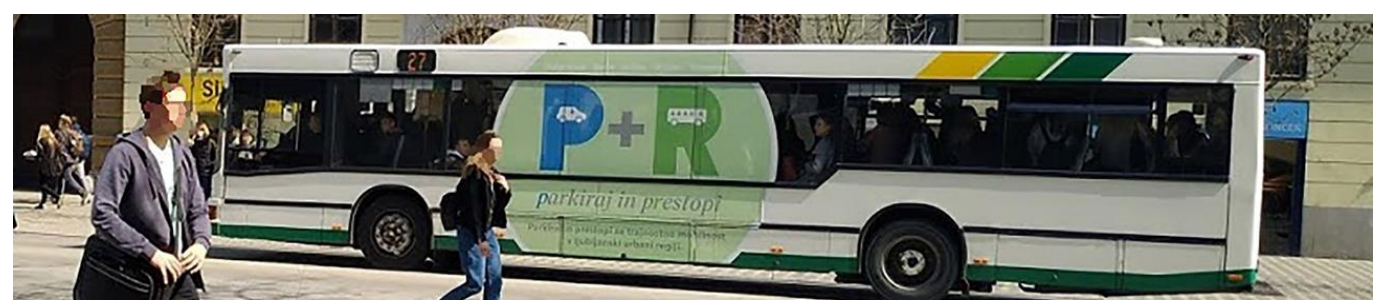

Figure 13: Ad for $P+R$ (Photo: A. Dujmović)

Figure 14 shows an ad that was not written by any of the respondents. The ad is small, covering the area between the first wheels and the second door. The inscription Kalček is not the most noticeable from a distance. The ad is probably aimed primarily at those who board the bus.

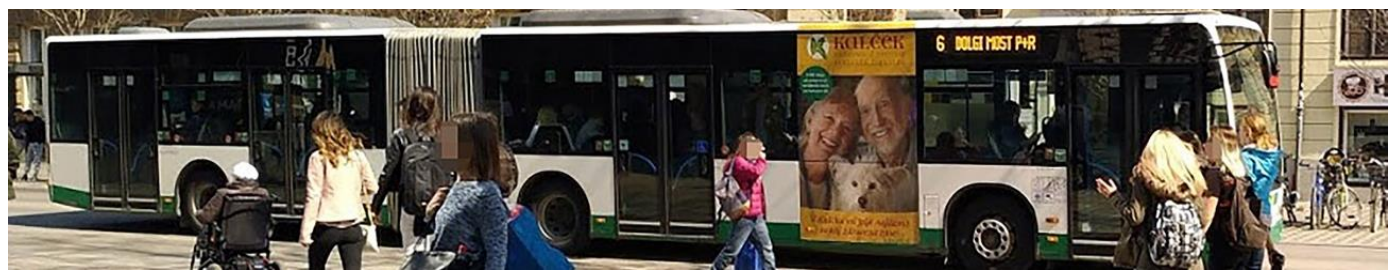

Figure 14: Ad for Kalček (Photo: A. Dujmović) 
Figure 15 shows an ad for Tuhelj Terms in Croatia. The entire left side, with the exception of the driver's window, is covered with an ad, a photo of the spa, a logo and a slogan in white. Nobody mentioned this ad, unfortunately we do not have data on when Tuhelj Terms started advertising on city buses in Ljubljana.

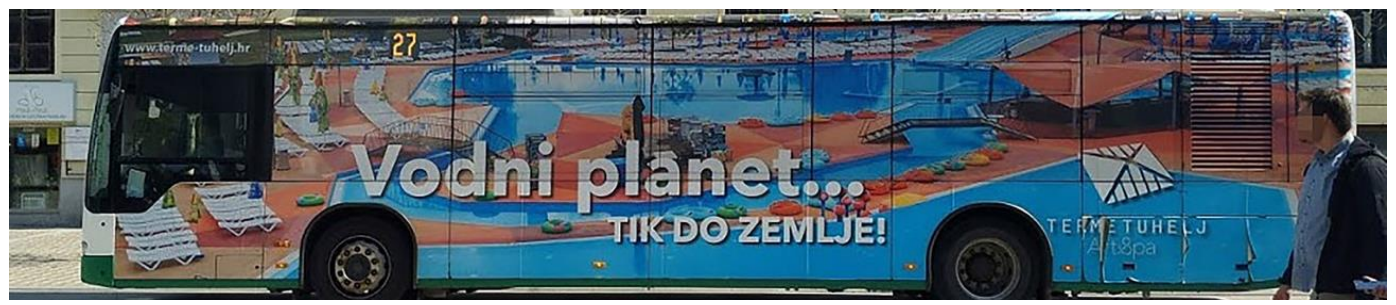

Figure 15: Ad for Tuhelj Terms, Croatia (Photo: A. Dujmović)

Interestingly, the ads cited by respondents were similar, despite companies offering different services. An analysis of the most frequently mentioned ads in the survey showed that:

- $\quad$ ads cover most of the bus, including glass surfaces;

- $\quad$ are presented in vivid colours that are well visible from a distance;

- used colours are consistent with the corporate visual identity of the company being advertised,

- have mostly small amount of text, e.g. a slogan that is well visible even from a greater distance.

$45(22.5 \%)$ people aged 25 to 34 do not agree at all with the fact that outdoor ads on the city buses in Ljubljana are interesting; other age groups opinion is between 28 (14.0\%) and 33 (16.5\%) (Figure 16). The majority $(55,27.5 \%)$ of respondents who do not agree with the statement are from the age group of 35 to 44 , and the remaining age groups range between 31 (15.5\%) and 42 (21.0\%). People under the age of 24 most often chose the answer neither agree nor disagree, $84(42.0 \%)$ were such, $44(22.0 \%)$ chose this answer in the age group 65 and higher; the remaining age groups range between 55 (27.5\%) and 72 (36.0\%). 71 (35.5\%) of people over the age of 65 agree that outdoor ads on the city buses are interesting, the remaining age groups are between 40 (20.0\%) and 72 (36.0\%). 19 (9,5\%) of those over 65 fully agreed with this statement and only $2(1.0 \%)$ of those between 35 and 44 , the remaining four groups ranging between 4 (2.0\%) and 9 (4.5\%).

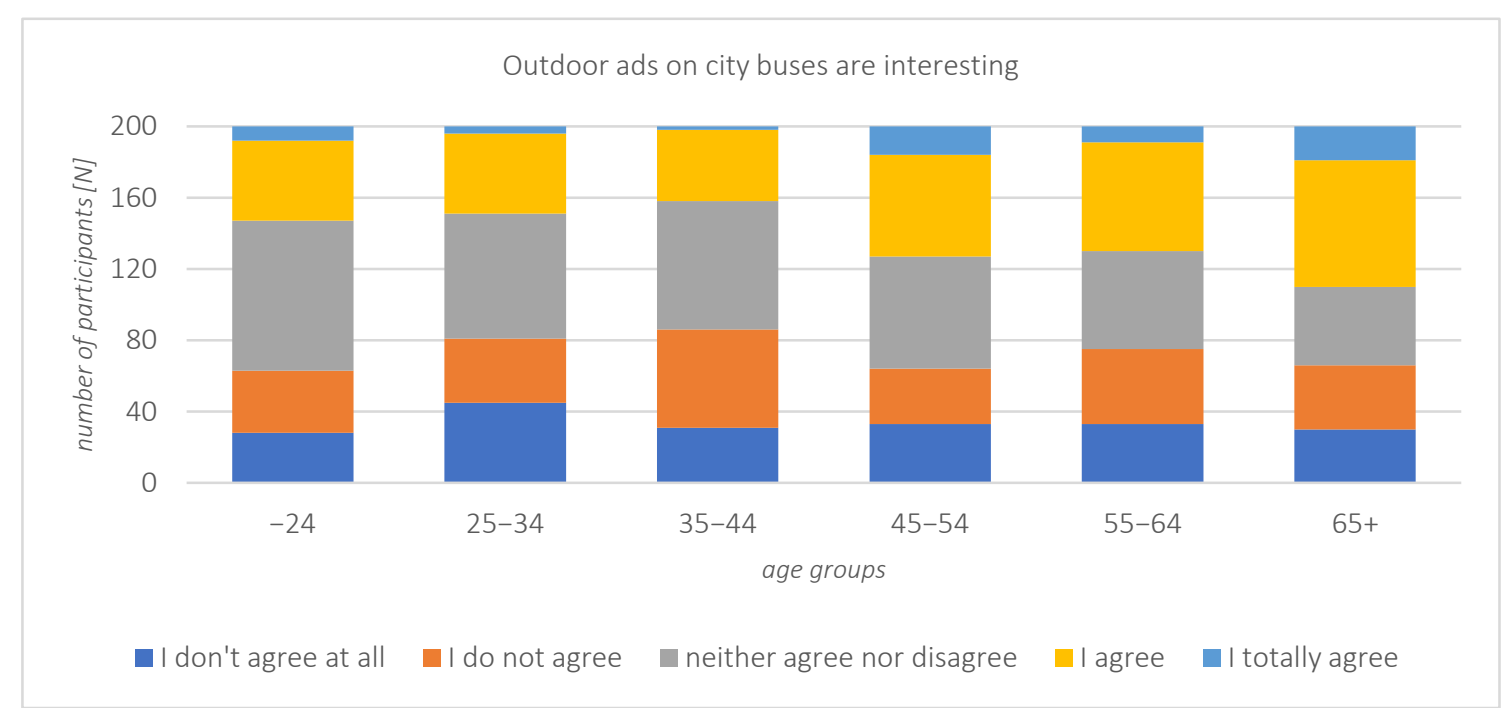

Figure 16: Display of agreement by age groups with the statement

"Outdoor ads on city buses in Ljubljana are interesting"

With the claim that outdoor ads on city buses offer useful information, 91 (45.5\%) people from group up to 24 years choose neither agree nor disagree. Dispersion of responses among other age groups was between 60 (30.0\%) and 77 (38.5\%) (Figure 17). 49 (24.5\%) people from group over 65 agreed with the statemen, the remaining age groups decided for this answer less often. No one in the 25 to 34 age group 
fully agreed that outdoor ads on buses offer useful information. Of the 1200 respondents, only 31 (2.6\%) fully agreed with this statement.

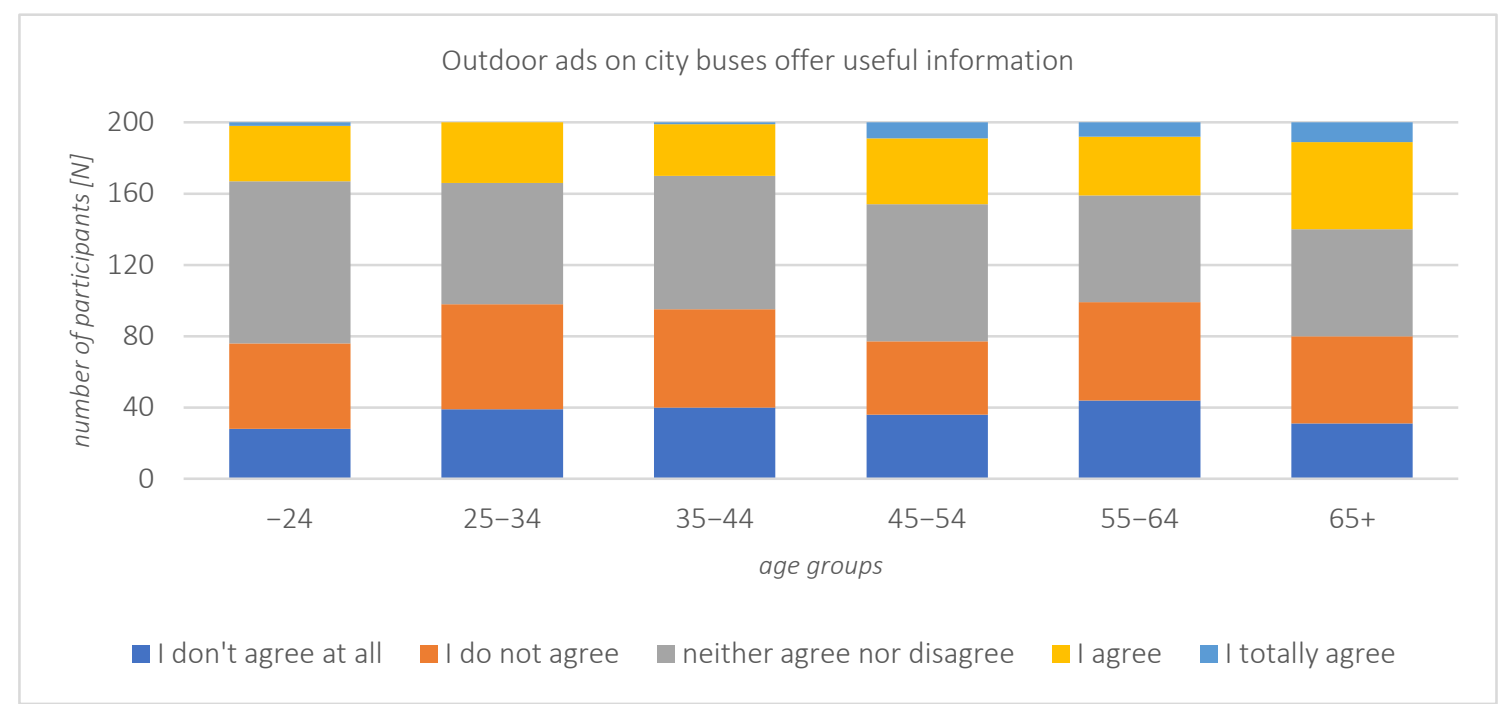

Figure 17: Display of agreement by age groups with the statement

"Outdoor ads on city buses in Ljubljana offer useful information"

$59(29.5 \%)$ of people aged 55 to 64 and same in group over 65 do not agree that they are disturbed by outdoor ads on city buses in Ljubljana. 46 (23.0\%) people under 24, over 65 and between 44 and 54 did not agree at all that they were bothered by outdoor ads; meaning 46 people in each age group (Figure 18). People between the ages of 35 and 44 agreed most with this statement, one quarter of them were from their age group, and the remaining age groups ranged between 24 (12.0\%) and 36 (18.0\%). 38 $(19.0 \%)$ of those aged 25 to 34 completely agreed with the statement, the remaining age groups are between 19 (9.5\%) and $32(16.0 \%)$.

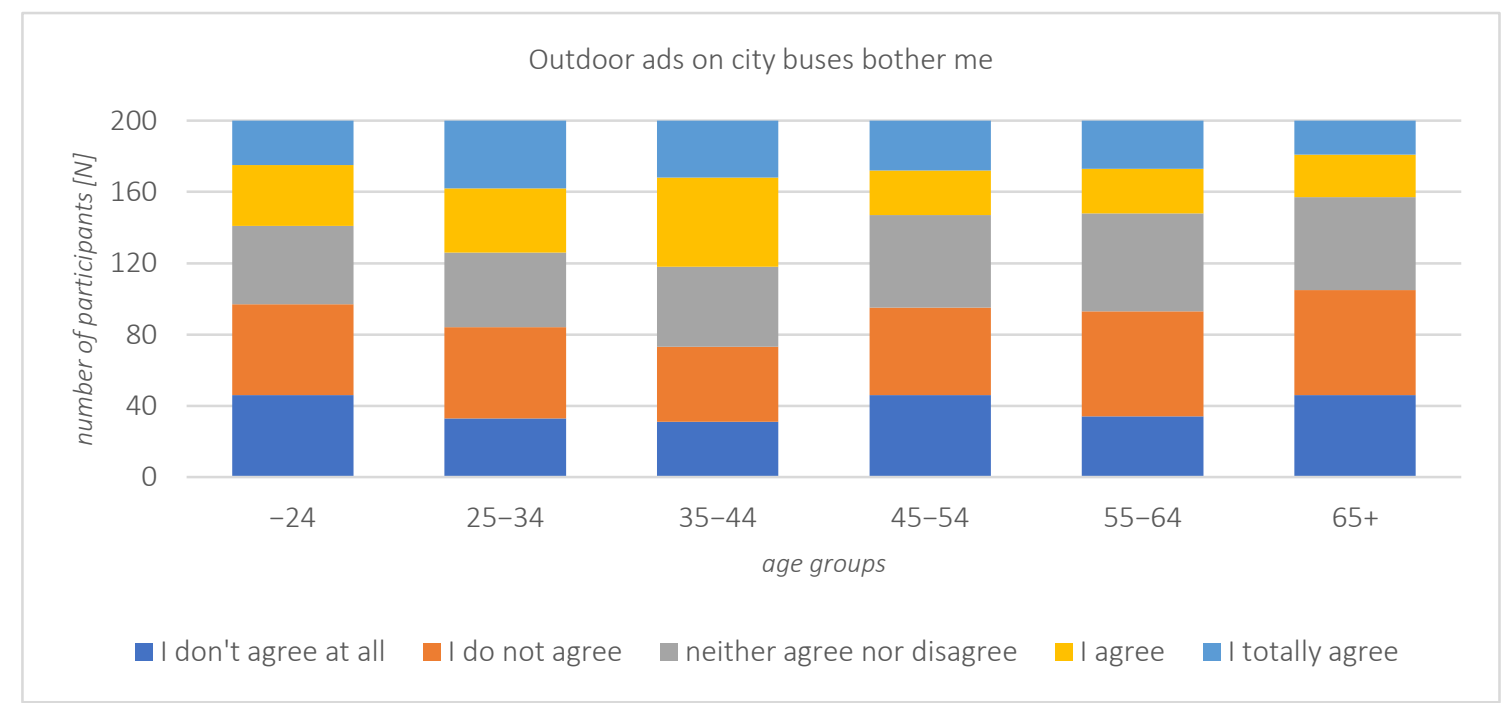

Figure 18: Display of agreement by age groups with the statement "Outdoor ads on city buses in Ljubljana bother me"

Figure 19 shows that there are no major discrepancies between the answers by age groups to the statement "Outdoor ads on city buses attract my attention". The largest deviation is $9.0 \%$ in the answer I do not agree at all between the age group 25-34 (11, 5.5\%) and 55 to 64 years $(29,14.5 \%)$. 


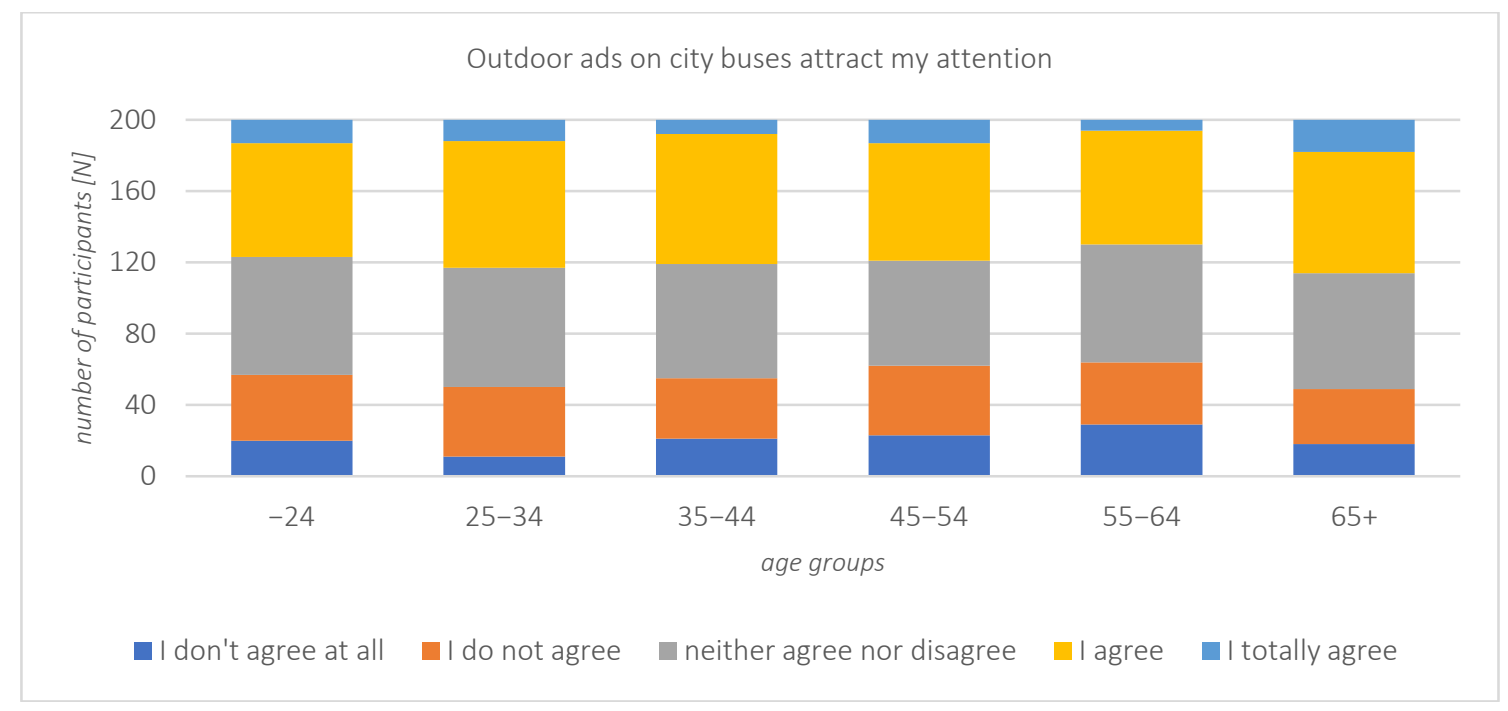

Figure 19: Display of agreement by age groups with the statement

"Outdoor ads on city buses in Ljubljana attract my attention"

61 (30.5\%) people under 24 and over 65 chose the option I agree with the statement that outdoor advertising on city buses in Ljubljana is an unobtrusive way of advertising; 61 participants in each group (Figure 20). Similar were response of the age group 55 to 64 (62, 31.0\%). 13 (6.5\%) of people aged 35 to 44, 55 to 64 and over 65 chose the option I totally agree with; 13 participants in each group. 30 (15.0\%) of people aged between 45 and 54 neither agree nor disagree with this statement, the remaining age groups are between $46(23.0 \%)$ and $57(28.5 \%)$ in this option. 56 (28.0\%) of people aged 45 to 54 do not agree that outdoor advertising is a smooth way of advertising, the remaining age groups are between 34 $(17.0 \%)$ and $49(24.5 \%)$.

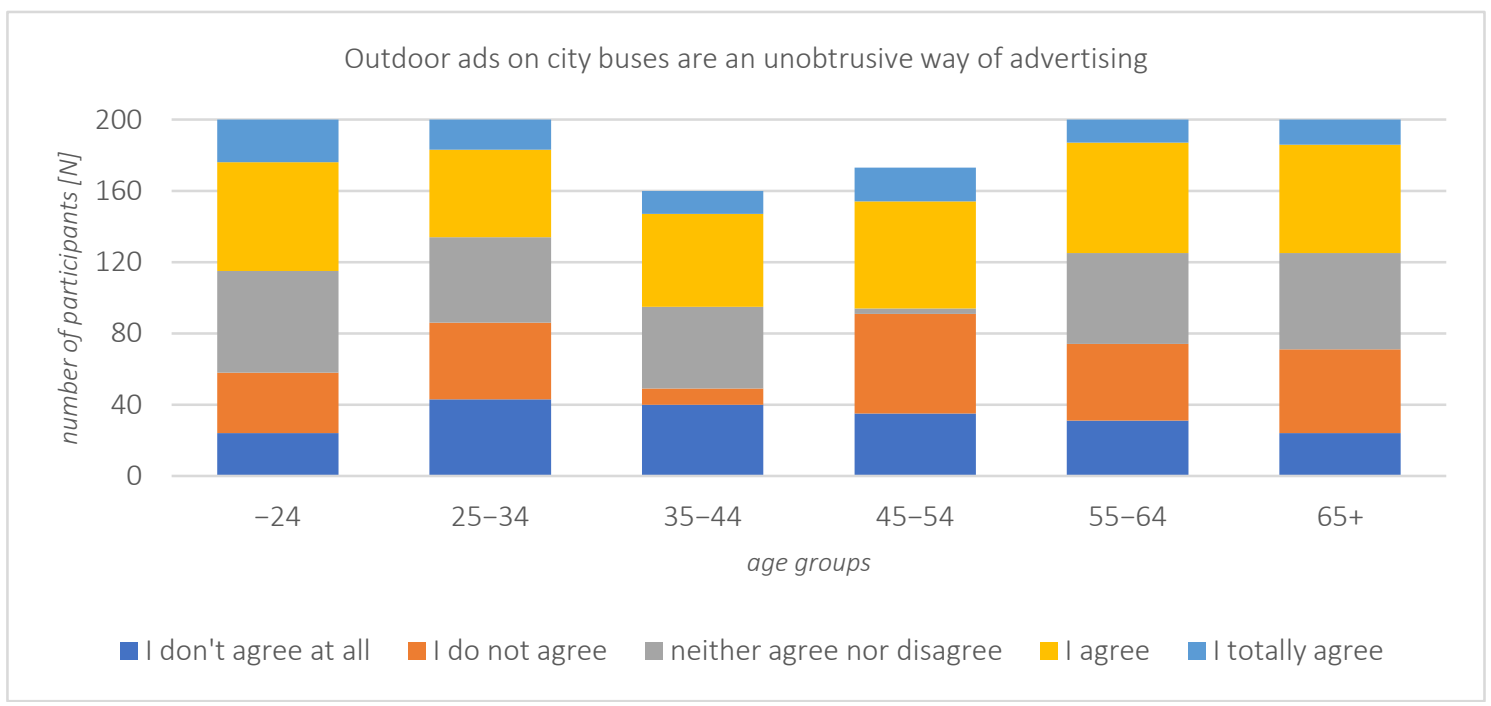

Figure 20: Display of agreement by age groups with the statement "Outdoor ads on city buses in Ljubljana are an unobtrusive way of advertising"

69 (34.5\%) of those aged 45 to 54 and 55 to 64 chose neither agree nor disagree with the statement that outdoor ads appear too often on buses in Ljubljana; 69 participants in each group (Figure 21). The option I do not agree was most often chosen by people under 24, 66 (33.0\%) of them, and least often by people aged 35 to 44, 38 (19.0\%) of them. At least often, respondents, regardless of age group, chose to disagree at all. 


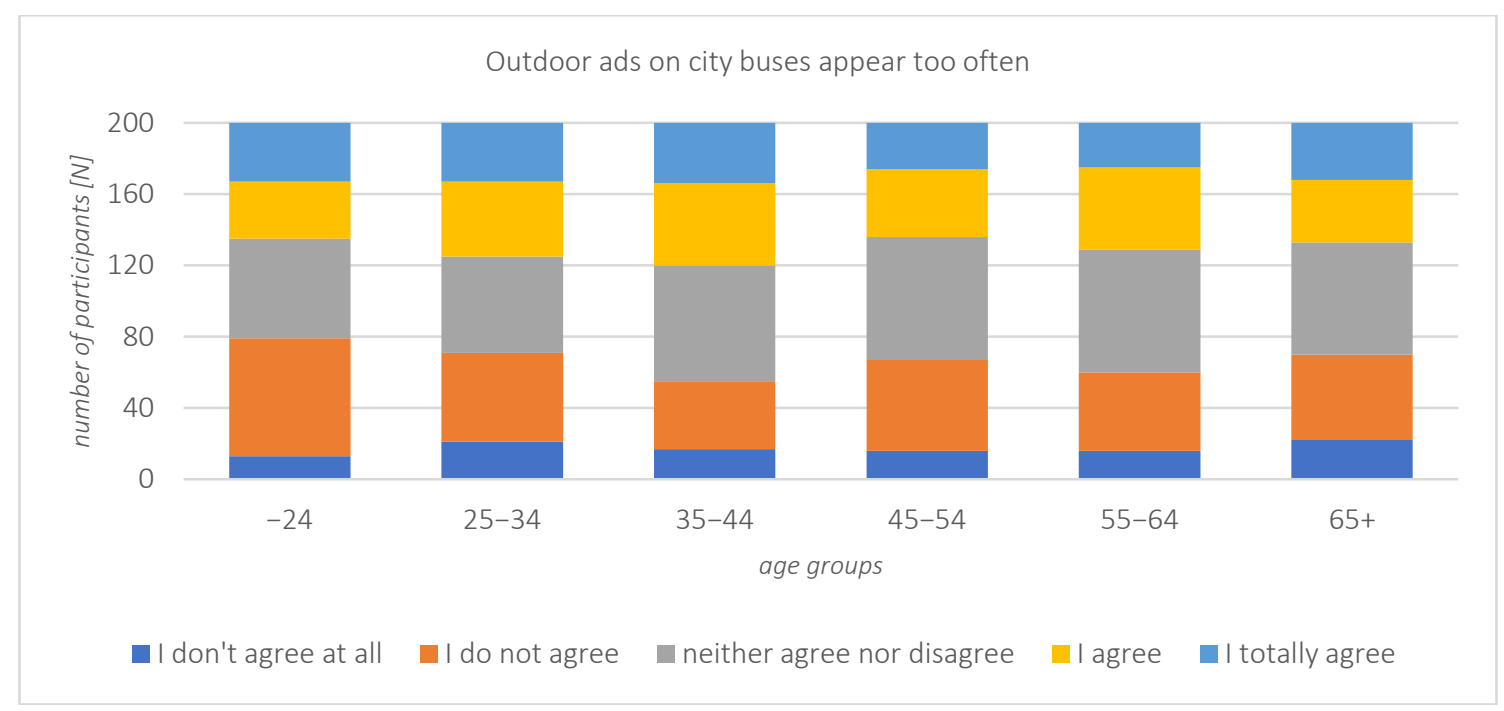

Figure 21: Display of agreement by age groups with the statement

"Outdoor ads on city buses in Ljubljana appear too often"

$68(34.0 \%)$ of the oldest and 66 (33.0\%) of the youngest chose not to agree with the fact that outdoor ads on buses in Ljubljana are too large. The remaining age groups participants were distributed between 35 $(17.5 \%)$ and $53(26.5 \%) .45(22.5 \%)$ of those aged 25 to 34 fully agree with the statement and $27(13.5 \%)$ of those over 65; this is also the lowest share for this answer (Figure 22).

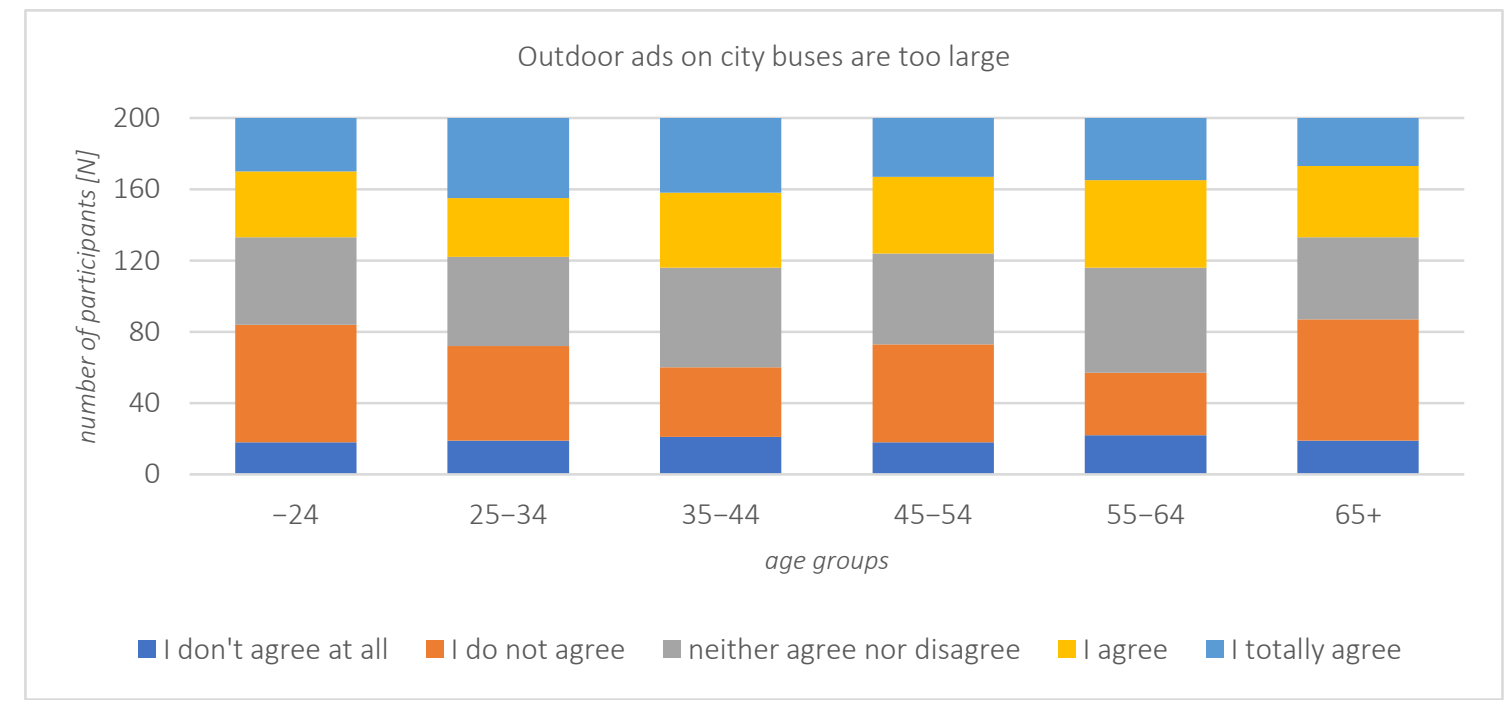

Figure 22: Display of agreement by age groups with the statement "Outdoor ads on city buses in Ljubljana are too big"

$83(41.5 \%)$ of those aged 25 to 34,81 (40.5\%) of those aged up to 24 and $80(40.0 \%)$ of those aged 35 to 44 fully agree that outdoor ads on city buses obstruct the view through the bus window (Figure 23). The least common choice was between 45 and 54 years old, 60 (30.0\%). 68 (34.0\%) of people under 24 agreed with the statement, the remaining groups ranged from 43 (21.5\%) (aged 25 to 34) to 55 (27.5\%) (35 to 44). The least common option is to either agree or disagree selected by the age group up to 24 . Disagree most commonly chose age group between 45 and 54 years, the remaining age groups are between $22(11.0 \%)$ and $31(15.5 \%)$. The least, $8(4.0 \%)$, aged up to 24 chose the option I do not agree at all; the most, $21(10.5 \%)$, chose this option between the ages of 45 and 54 . 


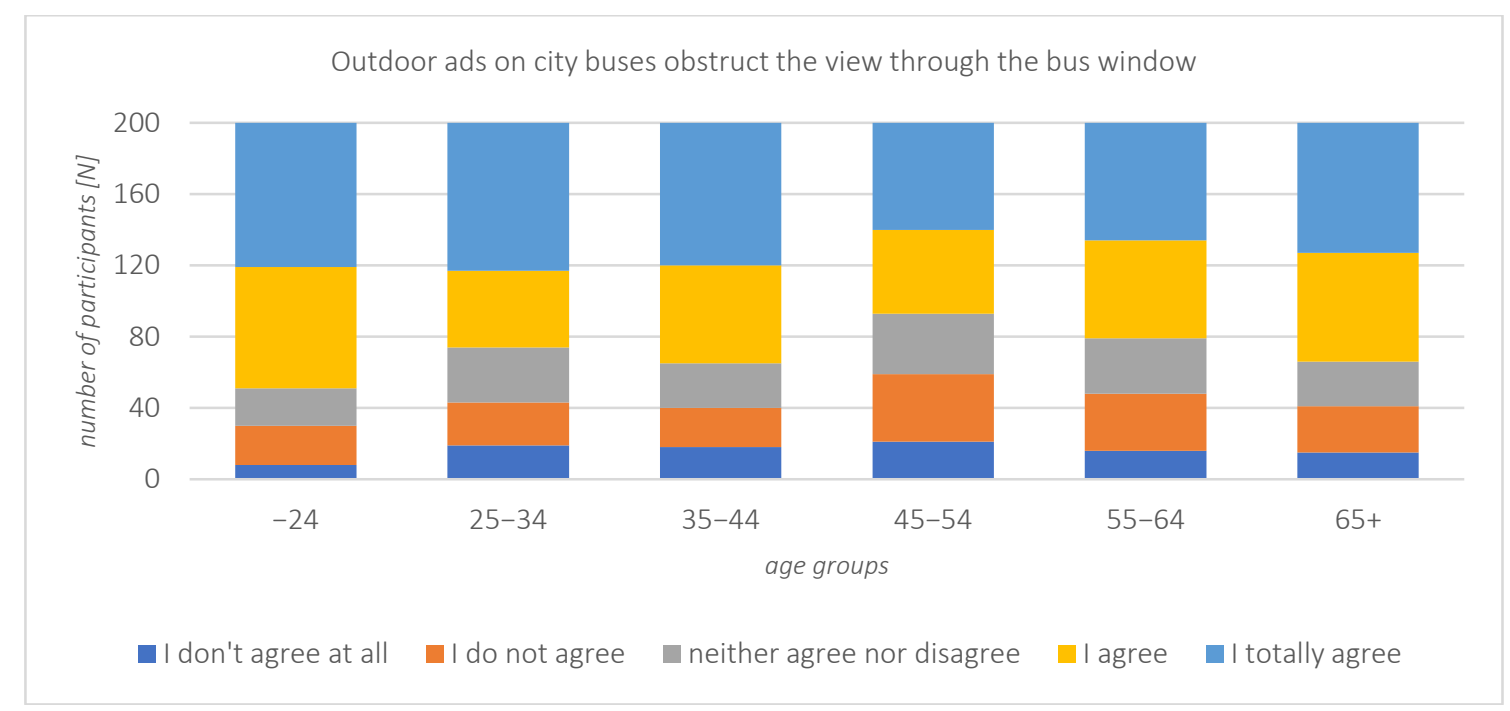

Figure 23: Display of agreement by age groups with the statement

"Outdoor ads on city buses in Ljubljana obstruct the view through the bus window"

\section{DISCUSSION}

In our research, we wanted to find out how people perceive outdoor ads on city buses in Ljubljana. We asked 1200 people about the opinion (field and online survey), which were divided into six age groups; each age group consisting of 100 women and 100 men. In this way, we obtained evenly distributed demographic data, which enabled more accurate and reliable comparison of the data. Most of the respondents were employed. 480 (40.0\%) of all respondents use the bus in Ljubljana occasionally. The frequency of bus use varies according to the age group. In the group up to 24 years old, bus is most often used four to six times a week; the remaining groups use the bus occasionally, and $132(11.0 \%)$ of all respondents do not use the city bus in Ljubljana.

It was found that $984(82.0 \%)$ of all respondents noticed at least one outdoor ad on a city buses in Ljubljana in the last week. The last week refers to the date of the survey. Interestingly, there were no major differences between women and men within the observation of ads on city buses. The youngest participants (group up to 24 years old) most often mentioned at least one ad that was on the outside of the city buses in Ljubljana (70, 35.0\%; the calculation is made based on 200 people in this age group). The difference between those aged up to 24 and those aged 55 to 64 and those over 65 , both of whom rarely mentioned an advertising message, is $23.0 \%$. Out of the 1200 respondents, $228(19.0 \%)$ cited at least one ad on the outside of the city buses.

We analyzed the ads mentioned by the respondents (Figures 8-13). The most frequently mentioned was ad for School B2; 18 (2.0\%) participants. We photographed the ads most frequently mentioned by the respondents and found out that they are covering most of one side of the bus. They are presented in vivid colours that also represent the corporate visual identity of a certain company. In most cases small amount of text is present.

Regarding the 5 hypotheses we posed.

- Hypothesis 1: 70\% or more of the respondents noticed at least one outdoor ad on a city buses in Ljubljana in the last week.

Hypothesis 1 is true because $82.0 \%$ (984) of all respondents noticed at least one outdoor ad on a city buses in Ljubljana.

- Hypothesis 2: 50\% or more of the respondents can state at least one advertising message that was on the outer part of the city buses in Ljubljana in the last week.

Hypothesis 2 is not true because only $19.0 \%$ (228) of respondents mentioned at least one ad that was on the city buses in Ljubljana.

- Hypothesis 3: $60 \%$ or more of the respondents think that outdoor ads on city buses in Ljubljana are interesting.

Hypothesis 3 is not true because $31.0 \%$ (372) of respondents agree or completely agree that outdoor ads on city buses in Ljubljana are interesting. 
- Hypothesis 4:50\% or more of the respondents believe that outdoor ads on city buses in Ljubljana are an unobtrusive way of advertising.

Hypothesis 4 is not true because $37.0 \%$ (444) of respondents agree or completely agree that outdoor ads on city buses in Ljubljana are an unobtrusive way of advertising.

- Hypothesis 5: 75\% or more of the respondents believe that outdoor ads on city buses in Ljubljana obstruct the view through the bus window.

Hypothesis 5 is not true because $64.0 \%$ (768) of respondents agree or completely agree that outdoor ads on city buses in Ljubljana obstruct the view through the bus window.

\section{CONCLUSIONS}

The analysis of the survey (field and online) showed that out of all statements about outdoor ads on city buses in Ljubljana, people most agree that outdoor ads on city buses in Ljubljana obstruct the view through the bus window. During the field survey, we heard some comments from respondents that because of the ads, they don't even see where they are, especially in bad (rainy) weather. Advertisers could take this into account and avoid sticking ads on the glass surfaces of buses, or limit this to the parts where ads are least annoying for bus users. They could cover those parts of the windows that users notice less, e.g. the back of the bus, the ad only at the bottom or top of the window. With this approach, the view through the windows would not be disturbed. On the other hand, it turned out that people most often cited ads that covered most of the bus side (including windows). Compromise about this is should be achieved.

In the future, the survey could be supplemented and checked how many of those who cited the ad later decided to buy certain product; what is the cost of a company that decides to advertise on city buses in Ljubljana, and how many new customers or users was gained because of this type of advertising. If we could ensure not to violate the provisions of the General Data Protection Regulation, we could carry out the recording with the help of an eye tracking device (glasses) and analyze how many users (passengers) look towards the city buses. Nevertheless, with the obtained data we can better know the opinion of people about ads on city buses in Ljubljana.

\section{REFERENCES}

[1] Ackley, C., Hackley, R. A.: "Advertising \& promotion", (SAGE Publications, London, 2015.)

[2] Allaby, M.: "Affinity Index - Encyclopedia.com", URL: https://www.encyclopedia.com/science/ dictionaries-thesauruses-pictures-and-press-releases/affinity-index (last request: 2020-08-09).

[3] Bernays, E. L.: "Propaganda", (Ig Publishing, Brooklyn NY, 2005.)

[4] De Pelsmacker, P., Geuens, M., Van den Bergh, J.: "Marketing Communications: A European Perspective", (Pearson, London, 2018.)

[5] Gregan-Paxton, J., Loken, B.: "Understanding Consumer Memory for Ads: Process View", In: Measuring Advertising Effectiveness, (Taylor and Francis, Philadephia PA, 1996.)

[6] Kovačič, A.: "How much attention does outdoor advertising attract and who profits", Innovative Issues and Approaches in Social Sciences 5 (3), 134-151, 2011. doi: 10.12959/issn.1855-0541.IIASS2012-no3-art08.

[7] Loken, B.: "Consumer Psychology: Categorization, inferences, affect, and persuasion", Annual Review of Psychology 57, 453-485, 2006. doi: 10.1146/annurev.psych.57.102904.190136.

[8] Media Bus: "Avtobusno oglaševanje", URL: http://mediabus.si/?page_id=35 (last request: 2020-0909).

[9] Mrgole, A.: "The influence on road safety due to driver distraction from outdoor advertising: case study", American Scientific Research Journal for Engineering Technology and Science 35 (11), 42-49, 2017.

[10] Phillips, M. D., Stanton, J. L.: "Age-related differences in advertising: recall and persuasion", Journal of Targeting, Measurement and Analysis for Marketing 13 (7-20), 2004. doi:

10.1057/palgrave.jt.5740128 
[11] Tsuji, R.: "What Factors Make Outdoor Advertising More Effective?: Effect of Corporate Color and Brand Image on the Recognition of Outdoor Advertising", URL: https://www.researchgate.net/ profile/Ryutaro_Tsuji/publication/296525779_What_Factors_Make_Outdoor_Advertising_More_Eff ective_Effect_of_Corporate_Color_and_Brand_Image_on_the_Recognition_of_Outdoor_Advertisin $\mathrm{g} /$ links/56d6654e08aee1aa5f7317ee/What-Factors-Make-Outdoor-Advertising-More-EffectiveEffect- (last-request 2017-01-10).

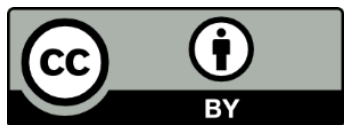

(C) 2020 Authors. Published by the University of Novi Sad, Faculty of Technical Sciences, Department of Graphic Engineering and Design. This article is an open access article distributed under the terms and conditions of the Creative Commons Attribution license 3.0 Serbia (http://creativecommons.org/licenses/by/3.0/rs/). 